\title{
Effects of atorvastatin on serum lipids, serum inflammation and plaque morphology in patients with stable atherosclerotic plaques
}

\author{
SUXIA GUO, RUXING WANG, ZHENYU YANG, KULIN LI and QIANG WANG
}

Department of Cardiology, Affiliated People's Hospital of Nanjing Medical University, Chong'an, Wuxi, Jiangsu 214023, P.R. China

Received July 1, 2012; Accepted September 14, 2012

DOI: $10.3892 /$ etm.2012.722

\begin{abstract}
Statin treatment in patients with coronary heart disease is associated with a reduced incidence of short-term adverse events and endpoint cardiac events. However, the effects of statin treatment on atherosclerotic plaques, particularly stable plaques, remain poorly defined. In total, 228 consecutive patients with stable atherosclerotic plaques who had undergone coronary arteriography (CAG) and intravascular ultrasound (IVUS) were randomly assigned to receive placebo (placebo group, $n=54$ ) or atorvastatin (ATOR) at a single daily dose of $10 \mathrm{mg}$ (ATOR $10 \mathrm{mg}$ group, $\mathrm{n}=47$ ), $20 \mathrm{mg}$ (ATOR $20 \mathrm{mg}$ group, $\mathrm{n}=45$ ), $40 \mathrm{mg}$ (ATOR $40 \mathrm{mg}$ group, $\mathrm{n}=43$ ) or $80 \mathrm{mg}$ (ATOR $80 \mathrm{mg}$ group, $\mathrm{n}=39$ ). Endpoints, including serum lipids, serum inflammation, plaque volume and percentage of plaque necrosis were assessed after 3-6 months. At baseline, mean low-density lipoprotein (LDL), high-density lipoprotein (HDL) and high-sensitivity C-reactive protein (hs-CRP) levels, as well as plaque volumes and percentages of plaque necrosis, were similar between all groups. At 6 months of follow-up, the LDL levels in the ATOR groups were below those at their respective baselines $(\mathrm{P}<0.01)$. HDL levels in the ATOR $80 \mathrm{mg}$ group following treatment were significantly higher compared with baseline $(\mathrm{P}=0.001)$. Additionally, they were significantly higher compared with those in the placebo, ATOR 10, 20 and $40 \mathrm{mg}$ groups $(\mathrm{P}<0.01$, $\mathrm{P}=0.001, \mathrm{P}=0.048, \mathrm{P}=0.047$, respectively). Hs-CRP levels in the placebo group following treatment were higher compared with baseline levels $(6.87 \pm 2.62$ vs. $5.07 \pm 1.80, \mathrm{P}<0.01)$, but hs-CRP levels in the ATOR $80 \mathrm{mg}$ group following treatment were lower compared with baseline $(3.59 \pm 1.07$ vs $6.10 \pm 2.12, \mathrm{P}<0.01)$. According to the virtual histology $(\mathrm{VH})$
\end{abstract}

Correspondence to: Professor Zhenyu Yang, Department of Cardiology, Affiliated People's Hospital of Nanjing Medical University in Wuxi and People's Hospital of Wuxi City, No.299 QingYang Road, Jiangsu 214023, P.R. China

E-mail: zhenyuyangcn@126.com

Key words: dose-ranging, atorvastatin, serum lipids, serum inflammation, plaque morphology, stable atherosclerotic plaques of IVUS, the percentages of plaque necrosis following treatment in the placebo and ATOR $10 \mathrm{mg}$ groups rose above baseline levels $(15.51 \pm 12.56$ vs. $7.69 \pm 1.31 \%, 13.54 \pm 11.76$ vs. $7.83 \pm 1.43 \%, \mathrm{P}<0.01)$ and conformed to the diagnostic criteria for unstable plaques $(15.51 \pm 12.56,13.54 \pm 11.76 \%)$. By contrast, in the ATOR 20, 40 and $80 \mathrm{mg}$ groups, percentages of plaque necrosis remained stable following treatment compared with baseline $(\mathrm{P}=0.069,0.846$ and 0.643 , respectively). Plaque volumes following treatment in the placebo, ATOR 10 and $20 \mathrm{mg}$ groups were similar to baseline levels. However, in the ATOR 40 and $80 \mathrm{mg}$ groups, plaque volumes decreased following treatment compared with baseline plaque volumes $\left(30.69 \pm 8.12\right.$ vs. $37.09 \pm 12.01 \mathrm{~mm}^{3}, 24.99 \pm 1.01$ vs. $36.47 \pm 14.68 \mathrm{~mm}^{3}, \mathrm{P}=0.019, \mathrm{P}<0.01$, respectively). ATOR (20 mg/day) is able to lower LDL to standard levels while ATOR $40 \mathrm{mg} /$ day was superior to $20 \mathrm{mg}$ /day and had similar effects to $80 \mathrm{mg} /$ day. Only ATOR $80 \mathrm{mg} /$ day was able to increase HDL levels. Hs-CRP in patients without ATOR was higher and ATOR $80 \mathrm{mg} /$ day decreased levels. ATOR $\geq 20 \mathrm{mg}$ /day is able to stabilize plaques and ATOR $80 \mathrm{mg} /$ day was superior to 20 and $40 \mathrm{mg} /$ day. Thus, ATOR 40-80 mg/day reduces the volume of plaques.

\section{Introduction}

Increasing evidence has shown that early and aggressive statin therapy decreases the risk of acute myocardial infarction (MI) and major adverse cardiovascular events (MACE) in patients with coronary heart disease (1-3). Several previous studies have also shown that cardiovascular morbidity and mortality in patients with hypercholesterolemia are significantly reduced by statins $(4,5)$. A meta-analysis of six trials in patients with stable angina revealed that statin pretreatment resulted in a $59.3 \%$ reduction of relative risk of procedural MI and a $20.5 \%$ overall reduction in MACE (6). Several studies have shown various loading doses of atorvastatin (ATOR) therapy prior to percutaneous coronary intervention to be associated with a reduced risk of MACE $(7,8)$. However, the effects of various loading doses of statins in patients with stable atherosclerotic plaques have not yet been evaluated. For this reason, a clinical follow-up study of various loading doses of ATOR on serum lipids, inflammation and plaque morphology in patients with stable atherosclerotic plaques was conducted. 
Coronary heart disease patients with stable atherosclerotic plaque $(\mathrm{n}=256)$

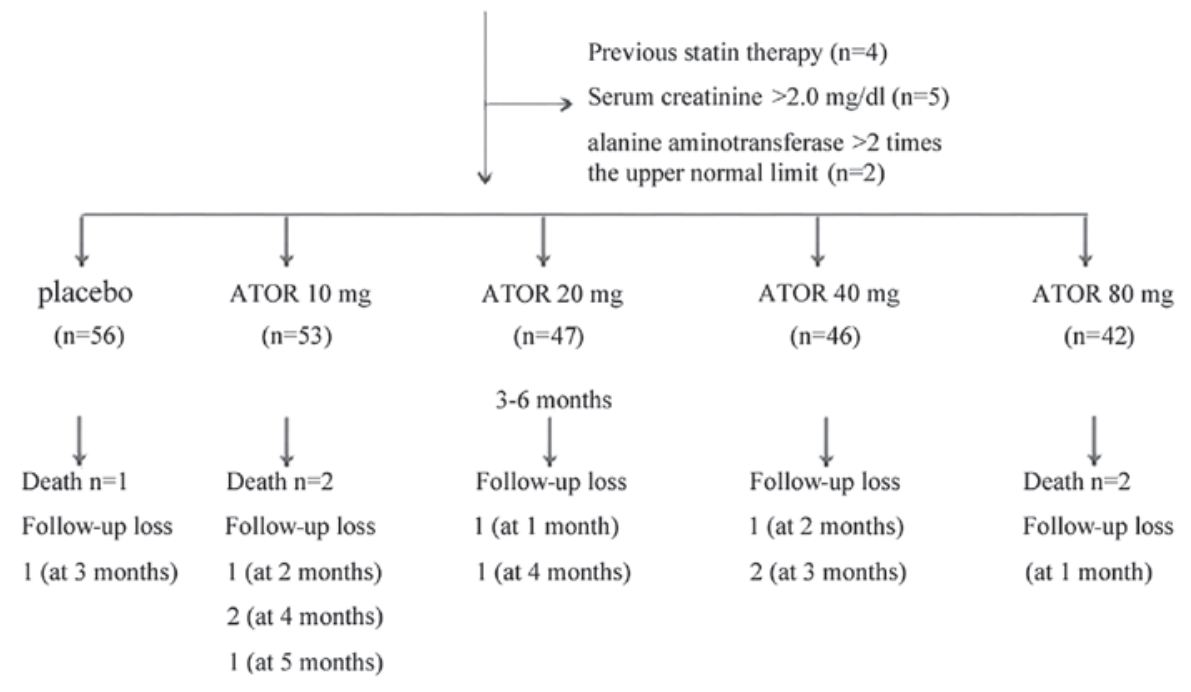

Figure. 1. Study design. ATOR, atorvastatin.

\section{Patients and methods}

Study population and design. The patients included in this study were recruited from Wuxi People's Hospital, Wuxi City, China, between May 2008 and December 2010. This study was conducted in accordance with the declaration of Helsinki and with approval from the Ethics Committee of Wuxi People's Hospital, Wuxi City, China. Written informed consent was obtained from all participants. In total, 256 consecutive patients with stable atherosclerotic plaques who had undergone diagnostic coronary angiography and intravascular ultrasound (IVUS) were screened. A total of 11 patients were excluded due to previous statin therapy, renal insufficiency (serum creatinine $>2.0 \mathrm{mg} /$ dayl) or hepatic disease (history of liver cirrhosis or alanine aminotransferase greater than twice the upper limit of normal). Eligible patients were randomly assigned to receive no statin treatment (placebo group) or to receive ATOR at a dosage of $10 \mathrm{mg}$ (ATOR $10 \mathrm{mg}$ ), $20 \mathrm{mg}$ (ATOR $20 \mathrm{mg}$ ), $40 \mathrm{mg}$ (ATOR $40 \mathrm{mg}$ ) or $80 \mathrm{mg}$ (ATOR $80 \mathrm{mg}$ ). Following six months, five patients had succumbed to the disease and nine patients were lost to follow-up. These patients were excluded and the remaining 228 patients were enrolled in the current study. The study took place after consent was obtained from all patients. The study design is shown in Fig. 1.

Aspirin (100 mg/day) was prescribed to all patients in this study. CK-MB and troponin T levels were measured prior to coronary angiography and IVUS. Additional cardiac enzyme measurements were obtained if the patients revealed signs or symptoms of myocardial ischemia. Low-density lipoprotein (LDL)-cholesterol, high-density lipoprotein (HDL)-cholesterol and high-sensitivity C-reactive protein (hs-CRP) levels were assessed prior to coronary angiography and IVUS. In all patients, angiotensin-converting enzyme inhibitor (ACEI), angiotensin receptor blocker (ARB) and beta blockers were administered according to blood pressure and heart rate.

Patients were followed up for 3-6 months at one-month intervals, through out-patient contact or by telephone. Ten patients were lost to follow-up prior to the end of the full 6-month follow-up period, but their data until this point were included in the statistical analysis. All patients provided written informed consent.

Coronary angiography and IVUS analysis. Coronary angiography and IVUS were performed during inpatient treatment (9). Within 3-6 months of coronary angiography, the site was selected for IVUS analysis of the coronary artery (10-12). All IVUS images were acquired using a $20-\mathrm{MHz}$ Volcano Eagle Eye ${ }^{\mathrm{TM}}$ IVUS catheter (Volcano Therapeutics Inc,. Rancho Cordova, CA, USA). Once the coronary lesion had been identified, the IVUS catheter was inserted distal to the lesion and manually pulled back to assess the severity and length of the lesion. The IVUS catheter was then placed distal to a side branch (distal fiduciary landmark site) and automatic pullback was performed at a rate of $0.5 \mathrm{~mm} / \mathrm{sec}$. The location of the IVUS catheter was determined using continuous fluoroscopy throughout the time of pullback and by recording anatomical landmarks observed during IVUS imaging. To create adequate images, an average of 2 pullbacks per artery were performed and the best play loop was selected based on imaging resolution and quality. Continuous EKG monitoring was performed during the procedure to gate IVUS frames for analysis. IVUS-virtual histology ( $\mathrm{VH})$ data were recorded to the imaging system hard drive and then extracted and archived for analysis. Analysis was based on border contour calculation from grayscale. The tissue maps provided by the software (dark green for fibrous tissue, light green for fibrofatty tissue, red for necrotic core and white for dense calcium) were used to analyze each independent frame. Once the total length of each lesion had been determined, a $20-\mathrm{mm}$ vascular segment containing the vascular lesion was selected for analysis. This segment was then divided into equal $2.0-\mathrm{mm}$ subsections, generating a total of 10 series of cross-sections per vascular segment. Unstable and stable plaques are shown in Fig. 2.

Endpoints. LDL levels $<2.06 \mathrm{mmol} / 1$ in patients with coronary heart disease were defined as normal. HDL levels $>1.0 \mathrm{mmol} / 1$ 
Table I. Baseline clinical characteristics.

\begin{tabular}{|c|c|c|c|c|c|c|}
\hline Characteristics & $\begin{array}{c}\text { Placebo } \\
(n=54)\end{array}$ & $\begin{array}{l}\text { ATOR } 10 \mathrm{mg} \\
\text { group }(\mathrm{n}=47)\end{array}$ & $\begin{array}{l}\text { ATOR } 20 \mathrm{mg} \\
\text { group }(n=45)\end{array}$ & $\begin{array}{l}\text { ATOR } 40 \mathrm{mg} \\
\text { group }(n=43)\end{array}$ & $\begin{array}{l}\text { ATOR } 80 \mathrm{mg} \\
\operatorname{group}(n=39)\end{array}$ & $\mathrm{F}\left(\chi^{2}\right) \mathrm{P}$-value \\
\hline Age (years) & $62.07 \pm 8.51$ & $62.64 \pm 12.00$ & $59.18 \pm 8.48$ & $58.91 \pm 12.90$ & $58.95 \pm 9.68$ & $9.085(0.059)$ \\
\hline Male/female & $48 / 6$ & $40 / 7$ & $36 / 9$ & $41 / 2$ & $34 / 5$ & $5.00(0.288)$ \\
\hline $\mathrm{FBG}(\mathrm{mmol} / \mathrm{l})$ & $5.26 \pm 0.98$ & $5.73 \pm 1.00$ & $5.72 \pm 0.82$ & $5.00 \pm 0.83$ & $5.63 \pm 0.97$ & $0.010(0.922)$ \\
\hline Alcohol (yes/no) & $33 / 21$ & $31 / 16$ & $25 / 20$ & $26 / 17$ & 20/19 & $2.246(0.690)$ \\
\hline Smoker (yes/no) & $46 / 8$ & $35 / 8$ & $35 / 10$ & $37 / 6$ & $32 / 7$ & $2.962(0.564)$ \\
\hline $\operatorname{LVEF}(\%)$ & $53.65 \pm 11.69$ & $55.15 \pm 13.16$ & $58.09 \pm 11.10$ & $57.14 \pm 10.34$ & $55.67 \pm 10.96$ & $1.095(0.360)$ \\
\hline Creatinine (mg/dl) & $85.11 \pm 21.63$ & $87.33 \pm 15.07$ & $81.57 \pm 16.93$ & $83.86 \pm 12.90$ & $88.11 \pm 15.28$ & $1.061(0.377)$ \\
\hline ACEI (yes/no) & $38 / 16$ & $31 / 16$ & $31 / 14$ & $33 / 10$ & $23 / 16$ & $3.027(0.524)$ \\
\hline Beta-blocker (yes/no) & $28 / 26$ & $29 / 18$ & $21 / 24$ & $21 / 22$ & $15 / 24$ & $4.927(0.295)$ \\
\hline
\end{tabular}

FBG, fasting blood glucose; LVEF, left ventricular ejection fraction. ATOR, atorvastatin; ACEI, angiotensin-converting enzyme inhibitor.

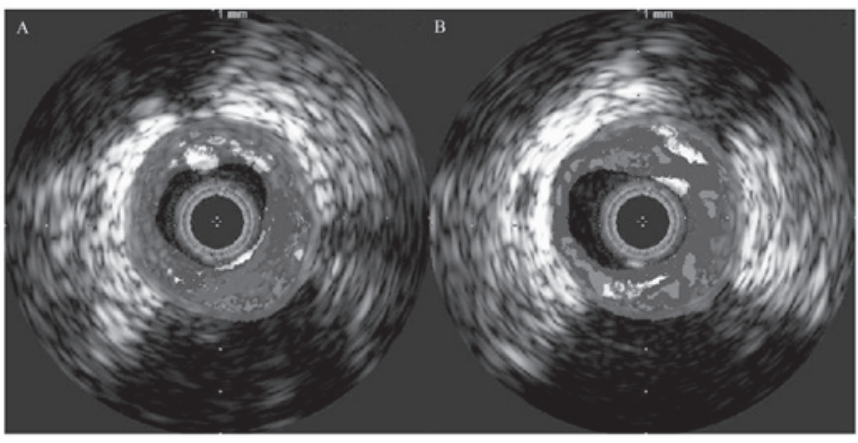

Figure 2. Intravascular ultrasound (IVUS) of two different plaques. (A) Unstable plaque. (B) Stable plaque.

and hs-CRP levels $<8 \mathrm{mg} / \mathrm{l}$ were defined as normal. Primary endpoints included changes in LDL, HDL and hs-CRP levels from baseline following 3-6 months of no treatment or ATOR treatment at the specified doses. Secondary endpoints included changes in the percentages of plaque necrosis and in plaque volumes. Stable plaques were defined as plaques with $<10 \%$ necrotic tissue. Plaque volumes $=\Sigma[$ (external elastic membrane cross-sectional area - lumen cross-sectional area)/the number of sections] x plaque length (3).

Statistical analyses. All measurements are shown as mean \pm standard deviation. Continuous variables between two groups were compared by independent t-tests and Chi-squared tests and multiple groups were compared by ANOVA. All tests were conducted using SPSS 17.0 software for Windows (Lei An Technology Company, Beijing City, China). Proportions were compared using Fisher's exact test when the expected frequency was $<5$ and Chi-squared testing in all other cases. $\mathrm{P}<0.05$ was considered to indicate a statistically significant result.

\section{Results}

Baseline characteristics. There were no significant differences between the five study groups in baseline and other clinical characteristics as shown in Table I. ATOR loading

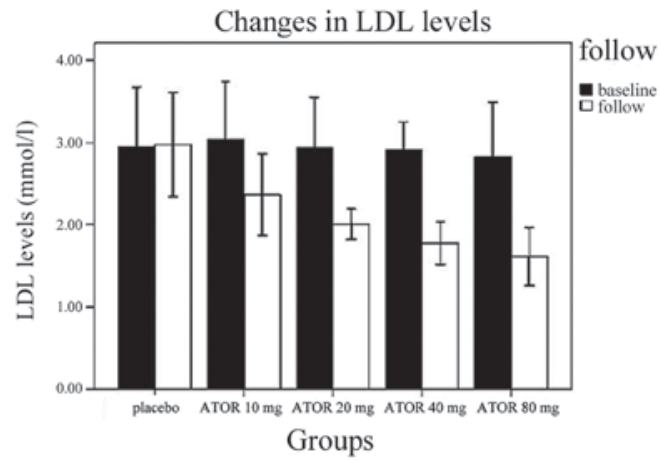

Figure 3. Changes in LDL at baseline and follow-up. LDL, low-density lipoprotein; ATOR, atorvastatin.

was performed for 3-6 months. VH of IVUS was used with procedural success achieved in all patients. Medication use was similar among groups, including the use of ACEI/ARB and beta blockers.

Primary endpoints. During the follow-up period (3-6 months, mean $4.51 \pm 1.23$ ), the endpoints of LDL, HDL and hs-CRP levels in the five treatment groups revealed significant differences from baseline. Changes in serum lipids and serum inflammation in groups are shown in Table II. LDL levels at follow-up in the placebo group demonstrated no change over baseline ( $\mathrm{P}=0.813$ ), but LDL levels at follow up in the ATOR $10,20,40$ and $80 \mathrm{mg}$ groups were lower than their respective baseline levels (all P<0.01). LDL levels in the ATOR $20 \mathrm{mg}$ group at follow-up were statistically significantly higher than in the ATOR $40 \mathrm{mg}(\mathrm{P}=0.048)$ and ATOR $80 \mathrm{mg}$ groups at follow-up ( $\mathrm{P}=0.001)$ and LDL levels in the ATOR $40 \mathrm{mg}$ group at follow-up were similar to the ATOR $80 \mathrm{mg}$ group $(\mathrm{P}=0.168)$. Changes in LDL at baseline and follow-up are shown in Fig. 3. HDL levels were significantly higher in the ATOR $80 \mathrm{mg}$ group following treatment than at baseline $(\mathrm{P}=0.001)$. HDL levels were also significantly higher in the ATOR $80 \mathrm{mg}$ group following treatment than in the placebo, ATOR 10,20 or $40 \mathrm{mg}$ groups $(\mathrm{P}<0.01, \mathrm{P}=0.001, \mathrm{P}=0.048$ and $\mathrm{P}=0.047$, respectively). 
Table II. Changes in serum lipids and serum inflammation in the study groups.

\begin{tabular}{|c|c|c|c|c|c|}
\hline Variable & $\begin{array}{c}\text { Placebo } \\
(n=54)\end{array}$ & $\begin{array}{l}\text { ATOR } 10 \mathrm{mg} \\
\operatorname{group}(\mathrm{n}=47)\end{array}$ & $\begin{array}{l}\text { ATOR } 20 \mathrm{mg} \\
\text { group }(\mathrm{n}=45)\end{array}$ & $\begin{array}{l}\text { ATOR } 40 \mathrm{mg} \\
\text { group }(\mathrm{n}=43)\end{array}$ & $\begin{array}{l}\text { ATOR } 80 \mathrm{mg} \\
\text { group }(\mathrm{n}=39)\end{array}$ \\
\hline \multicolumn{6}{|c|}{ HDL (mmol/l) } \\
\hline Baseline & $0.96 \pm 0.18$ & $0.90 \pm 0.17$ & $0.93 \pm 0.20$ & $0.97 \pm 0.24$ & $0.90 \pm 0.13$ \\
\hline Follow-up & $0.89 \pm 0.17$ & $0.90 \pm 0.16$ & $0.96 \pm 0.14$ & $0.96 \pm 0.22$ & $1.03 \pm 0.22$ \\
\hline \multicolumn{6}{|c|}{$\mathrm{LDL}(\mathrm{mmol} / \mathrm{l})$} \\
\hline Baseline & $2.94 \pm 0.72$ & $3.03 \pm 0.70$ & $2.92 \pm 0.62$ & $2.90 \pm 0.34$ & $2.83 \pm 0.66$ \\
\hline Follow-up & $2.97 \pm 0.63$ & $2.36 \pm 0.50$ & $2.01 \pm 0.18$ & $1.85 \pm 0.22$ & $1.81 \pm 0.32$ \\
\hline \multicolumn{6}{|c|}{ Hs-CRP (mg/l) } \\
\hline Baseline & $5.07 \pm 1.80$ & $6.04 \pm 2.52$ & $5.09 \pm 1.94$ & $5.67 \pm 2.22$ & $6.10 \pm 2.12$ \\
\hline Follow-up & $6.87 \pm 2.62$ & $6.74 \pm 2.20$ & $5.07 \pm 1.72$ & $4.88 \pm 1.52$ & $3.59 \pm 1.07$ \\
\hline
\end{tabular}

Values are expressed as mean \pm standard deviation. HDL, high-density lipoprotein; LDL, low-density lipoprotein; hs-CRP, high-sensitivity C-reactive protein; ATOR, atorvastatin.

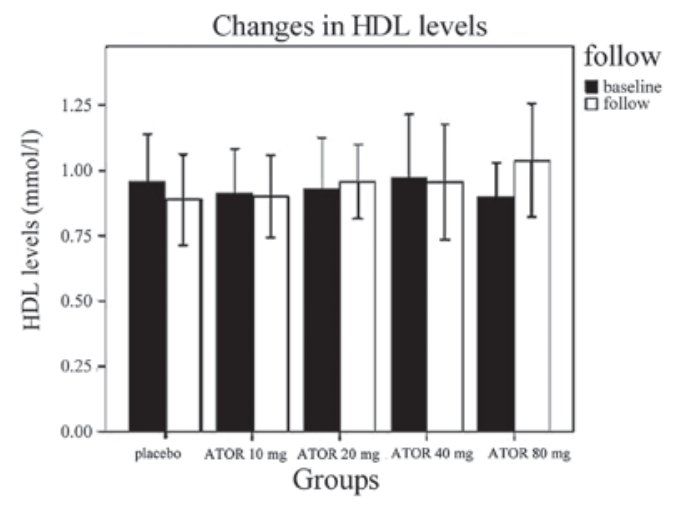

Figure 4. Changes in HDL at baseline and follow-up. HDL, high-density lipoprotein; ATOR, atorvastatin.

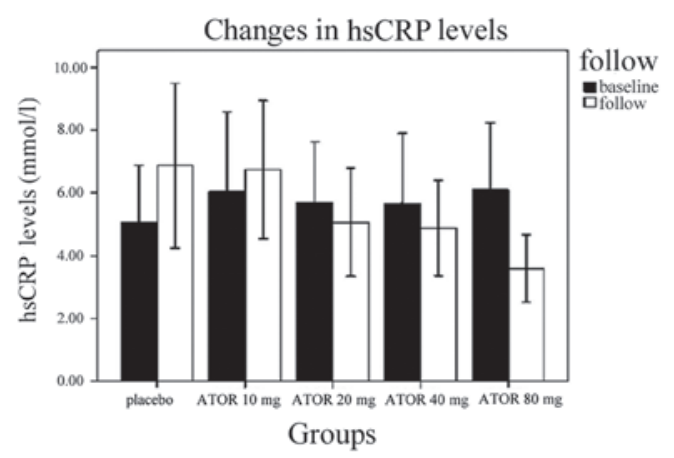

Figure 5. Changes in hs-CRP at baseline and follow-up. Hs-CRP, highsensitivity C-reactive protein; ATOR, atorvastatin.

However, there were no significant differences between HDL levels amongst the placebo, ATOR 10, 20 or $40 \mathrm{mg}$ groups. Changes in HDL at baseline and follow-up are shown in Fig. 4. Hs-CRP levels at follow-up in the placebo group were higher than baseline $(6.87 \pm 2.62$ vs. $5.07 \pm 1.80, \mathrm{P}<0.01)$, while those in the ATOR $80 \mathrm{mg}$ group following treatment were lower than at baseline $(3.59 \pm 1.07$ vs. $6.10 \pm 2.12, \mathrm{P}<0.01)$. There were no

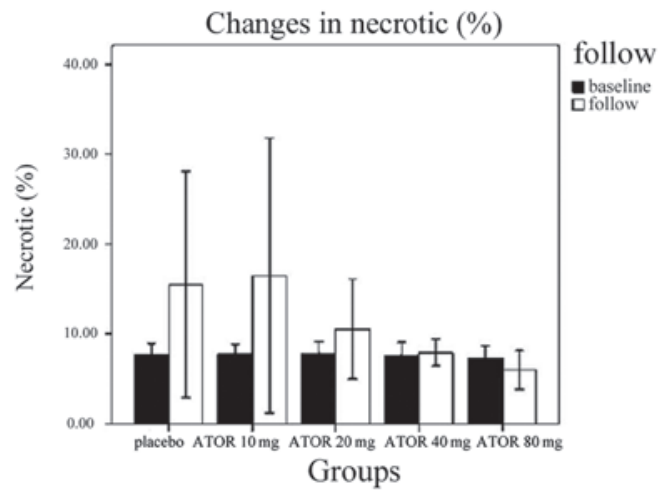

Figure 6. Changes in the relative amount of necrotic tissue at baseline and follow-up. ATOR, atorvastatin.

statistically significant differences between hs-CRP following treatment than at baseline for the ATOR $10 \mathrm{mg}$, ATOR $20 \mathrm{mg}$ and ATOR $40 \mathrm{mg}$ groups, but higher dosages of ATOR were generally associated with trends toward maintaining or decreasing hs-CRP levels over time with treatment. Changes in hs-CRP at baseline and follow-up are shown in Fig. 5.

Secondary endpoints. According to the VH of IVUS, the percentages of plaque necrosis on follow-up increased in the placebo and ATOR $10 \mathrm{mg}$ groups, compared with baseline percentages $(15.51 \pm 12.56$ vs. $7.69 \pm 1.31 \%, 13.54 \pm 11.76$ vs. $7.83 \pm 1.43 \%, \mathrm{P}<0.01$ ), satisfying the diagnostic criteria for unstable plaques. In the ATOR 20, 40 and $80 \mathrm{mg}$ groups no differences in percentages of plaque necrosis from baseline were observed $(\mathrm{P}=0.069,0.846,0.643$, respectively). In the placebo, ATOR 10 and $20 \mathrm{mg}$ groups, plaque volumes did not increase relative to their respective baselines. By contrast, in the ATOR 40 and $80 \mathrm{mg}$ groups, plaque volumes decreased relative to their respective baselines $(30.69 \pm 8.12$ vs. $37.09 \pm 12.01 \mathrm{~mm}^{3}, 24.99 \pm 1.01$ vs. $36.47 \pm 14.68 \mathrm{~mm}^{3}, \mathrm{P}=0.019$, $\mathrm{P}<0.01)$. Changes in the percentages of plaque necrosis and plaque volumes in groups are shown in Table III, Figs. 6 and 7 
Table III. Changes of the percentages of plaque necrosis and plaque volumes in groups.

\begin{tabular}{|c|c|c|c|c|c|}
\hline Variable & $\begin{array}{c}\text { Placebo } \\
(n=54)\end{array}$ & $\begin{array}{l}\text { ATOR } 10 \mathrm{mg} \\
\text { group }(\mathrm{n}=47)\end{array}$ & $\begin{array}{l}\text { ATOR } 20 \mathrm{mg} \\
\operatorname{group}(\mathrm{n}=45)\end{array}$ & $\begin{array}{l}\text { ATOR } 40 \mathrm{mg} \\
\text { group }(n=43)\end{array}$ & $\begin{array}{l}\text { ATOR } 80 \mathrm{mg} \\
\text { group }(\mathrm{n}=39)\end{array}$ \\
\hline \multicolumn{6}{|l|}{ Necrotic (\%) } \\
\hline Baseline & $7.69 \pm 1.31$ & $7.83 \pm 1.03$ & $7.91 \pm 1.27$ & $7.64 \pm 1.44$ & $7.38 \pm 1.33$ \\
\hline Follow-up & $15.51 \pm 12.65$ & $16.54 \pm 15.76$ & $10.55 \pm 5.56$ & $7.93 \pm 1.49$ & $6.66 \pm 1.92$ \\
\hline \multicolumn{6}{|c|}{ Plaque volume $\left(\mathrm{mm}^{3}\right)$} \\
\hline Baseline & $34.83 \pm 13.76$ & $38.07 \pm 13.94$ & $33.83 \pm 10.56$ & $37.06 \pm 12.01$ & $36.47 \pm 14.68$ \\
\hline Follow-up & $37.46 \pm 15.80$ & $38.05 \pm 13.56$ & $36.12 \pm 11.96$ & $30.69 \pm 8.12$ & $24.99 \pm 1.01$ \\
\hline
\end{tabular}

Values are expressed as mean \pm standard deviation. ATOR, atorvastatin.

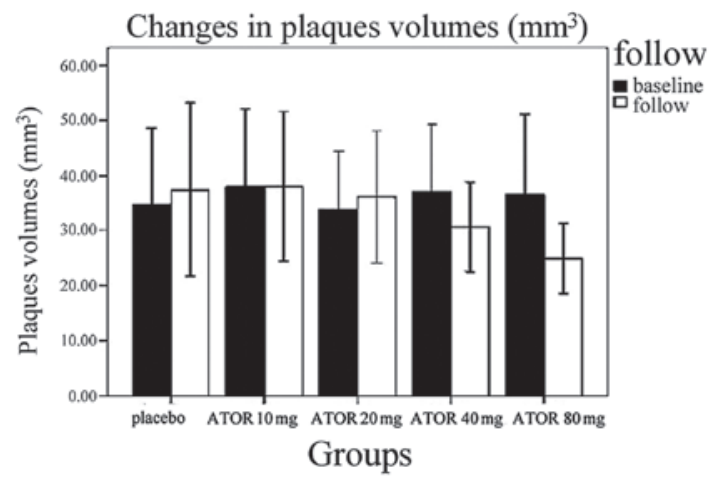

Figure 7. Changes in plaque volume at baseline and follow-up. ATOR, atorvastatin.

\section{Discussion}

In the present dose-ranging study of ATOR in patients with stable coronary atherosclerotic plaques, the dose-dependent effects of ATOR on serum lipids, serum inflammation and plaque morphology were demonstrated. In general, higher dosages of ATOR up to $80 \mathrm{mg}$ per day for up to 3-6 months of treatment were associated with a greater potential for beneficial effects by decreasing LDL, increasing HDL, decreasing hs-CRP, preventing plaque necrosis and reducing plaque volume in patients with stable coronary atherosclerotic plaques.

Previous studies have demonstrated that statin therapy improves the prognosis of patients with coronary heart disease (13-15). The PROVEIT study reported that a dose of $80 \mathrm{mg}$ ATOR per day reduced the risk of negative outcomes at 30 days and 2 years (16). The MIRACL study revealed that $80 \mathrm{mg}$ ATOR per day reduced the risk of the composite primary endpoints comprising mortality, MI, cardiac arrest and recurrent ischemia (17). The study indicated that high, early doses of statin therapy significantly improved the prognosis in patients with heart disease. A meta-analysis of six trials (6) in patients with stable angina revealed that statin pretreatment was associated with a $59.3 \%$ reduction in the relative risk of procedural $\mathrm{MI}$ and a $20.5 \%$ overall reduction in MACE. Several studies have been performed to evaluate the benefits of high doses of statins in patients with heart disease (18-20). However, to date, no studies have evaluated the effects of various doses of ATOR on stable atheroscletotic plaques.

In the current study, the age, male-to-female ratio, history of diabetes and hypertension, history of alcohol use and smoking, pre-treatment medication regimen (including ACEI, ARB and beta blockers), as well as pre-treatment serum lipid levels and hs-CRP levels, of the patients were not significantly different between the five groups.

Following treatment, the LDL, HDL and hs-CRP levels differed among the five groups. For LDL, the use of ATOR at $20 \mathrm{mg} /$ day brought LDL levels down to the standard value, while 40 and $80 \mathrm{mg} / \mathrm{day}$ were identified to be similar to each other and more effective than $20 \mathrm{mg} / \mathrm{day}$ in lowering LDL levels. Treatment with $80 \mathrm{mg} /$ day increased HDL levels and no effect was observed with any of the lower dosages. In patients who were not administered statins, the hs-CRP levels increased relative to baseline, but $80 \mathrm{mg}$ /day ATOR lowered hs-CRP levels. Doses of $20 \mathrm{mg} /$ day and higher kept plaques stable as demonstrated by prevention of progressive plaque necrosis with treatment, compared with no treatment. In addition, $80 \mathrm{mg}$ /day was revealed to be significantly more effective than 20 or $40 \mathrm{mg} /$ day at decreasing plaque volume. This indicated dose-dependent effects of ATOR on clinically relevant serum lipid and inflammatory markers as well as in plaque morphology in patients with stable atherosclerotic plaques.

The current study has several limitations. Firstly, the study was not blinded. Secondly, the sample size was relatively small. Finally, the duration of follow-up was relatively short. Of note, our original study design called for two years of follow-up, but the study was stopped early due to statistically significant results being obtained on interim analysis after 3 and 6 months of follow-up. Further study is required to confirm our results, ideally in an independent sample population.

In conclusion, ATOR at a dosage of $80 \mathrm{mg} /$ day for 6 months is associated with improvements in the serum lipid profile, decrease in serum inflammation and the maintenance of plaque stability in patients with stable coronary atherosclerotic plaques. Several of these potentially beneficial effects were also observed at lower dosages of ATOR, but these effects were more marked and consistent at $80 \mathrm{mg} /$ day. 


\section{References}

1. Schwartz GG, Olsson AG, Ezekowitz MD, et al; Myocardial Ischemia Reduction with Aggressive Cholesterol Lowering (MIRACL) Study Investigators: Effects of atorvastatin on early recurrent ischemic events in acute coronary syndromes: the MIRACL study: a randomized controlled trial. JAMA 285: 1711-1718, 2001.

2. Ray KK, Cannon CP, McCabe CH, et al; PROVE IT-TIMI 22 Investigators: Early and late benefits of high-dose atorvastatin in patients with acute coronary syndromes: results from the PROVE IT-TIMI 22 trial. J Am Coll Cardiol 46: 1405-1410, 2005.

3. Ishizu T, Seo Y, Machino T, et al: Prognostic impact of plaque echolucency in combination with inflammatory biomarkers on cardiovascular outcomes of coronary artery disease patients receiving optimal medical therapy. Atherosclerosis 216: 120-124, 2011.

4. Downs JR, Clearfield M, Weis S, et al: Primary prevention of acute coronary events with lovastatin in men and women with average cholesterol levels: results of AFCAPS/TexCAPS. Air Force/Texas Coronary Atherosclerosis Prevention Study. JAMA 279: 1615-1622, 1998.

5. Yokoi H,Nobuyoshi M,MitsudoK,Kawaguchi A and Yamamoto A; ATHEROMA Study Investigators: Three-year follow-up results of angiographic intervention trial using an HMG-CoA reductase inhibitor to evaluate retardation of obstructive multiple atheroma (ATHEROMA) study. Circ J 69: 875-883, 2005.

6. Ebrahimi R, Saleh J, Toggart E, et al: Effect of preprocedural statin use on procedural myocardial infarction and major cardiac adverse events in percutaneous coronary intervention: a metaanalysis. J Invasive Cardiol 20: 292-295, 2008.

7. Cahoon WD Jr and Crouch MA: Preprocedural statin therapy in percutaneous coronary intervention. Ann Pharmacother 41: 1687-1693, 2007.

8. Ko DT, Wijerysundera HC, Yun L, Austin PC, Cantor WJ and Tu JV: Effectiveness of preprocedural statin therapy on clinical outcomes for patients with stable coronary artery disease after percutaneous coronary interventions. Circ Cardiovasc Qual Outcomes 4: 459-466, 2011.

9. Wakabayashi K, Mintz G, Delhaye C, et al: In vivo virtual histology intravascular ultrasound comparison of neointimal hyperplasia within drug-eluting- versus bare metal stents. J Invasive Cardiol 23: 262-268, 2011.

10. Mintz GS, Nissen SE, Anderson WD, et al: American College of Cardiology clinical expert consensus document on standards for acquisition, measurement and reporting of intravascular ultrasound studies (IVUS). A report of the American College of Cardiology Task Force on Clinical Expert Consensus Documents. J Am Coll Cardiol 37: 1478-1492, 2001.
11. Schoenhagen P, Sapp K, Tuzcu EM, et al: Variability of area measurements obtained with different intravascular ultrasound catheter systems: Impact on clinical trials and a method for accurate calibration. J Am Soc Echocardiogr 16: 277-284, 2003.

12. Nasu K, Tsuchikane E, Katoh O, et al: Effect of fluvastatin on progression of coronary atherosclerotic plaque evaluated by virtual histology intravascular ultrasound. JACC Cardiovasc Interv 2: 689-696, 2009.

13. Capurso A: The promise of statins. Ital Heart J Suppl 2: 224-229, 2001 (In Italian).

14. Parolari A, Tremoli E, Cavallotti L, et al: Do statins improve outcomes and delay the progression of non-rheumatic calcific aortic stenosis? Heart 97: 523-529, 2011.

15. van der Loo B, Spring S and Koppensteiner R: High-dose ATOR treatment in patients with peripheral arterial disease: effects on platelet aggregation, blood rheology and plasma homocysteine. Clin Hemorheol Microcirc 47: 241-251, 2011.

16. Murphy SA, Cannon CP, Wiviott SD, McCabe $\mathrm{CH}$ and Braunwald E: Reduction in recurrent cardiovascular events with intensive lipid-lowering statin therapy compared with moderate lipid-lowering statin therapy after acute coronary syndromes from the PROVE IT-TIMI 22 (Pravastatin or Atorvastatin Evaluation and Infection Therapy-Thrombolysis in Myocardial Infarction 22) trial. J Am Coll Cardiol 54: 2358-2362, 2009.

17. Kinlay S, Schwartz GG, Olsson AG, et al; Myocardial Ischemia Reduction with Aggressive Cholesterol Lowering (MIRACL) Study Investigators: Inflammation, statin therapy, and risk of stroke after an acute coronary syndrome in the MIRACL study. Arterioscler Thromb Vasc Biol 28: 142-147, 2008.

18. Baigent C, Keech A, Kearney PM, et al; Cholesterol Treatment Trialists' (CTT) Collaborators: Efficacy and safety of cholesterollowering treatment: prospective meta-analysis of data from 90,056 participants in 14 randomised trials of statins. Lancet 366: 1267-1278, 2005.

19. Tziakas DN, Chalikias GK, Stakos D, et al: Statin use is associated with a significant reduction in cholesterol content oferythrocyte membranes. A novel pleiotropic effect? Cardiovasc Drugs Ther 23: 471-480, 2009.

20. Chan DK, O'Rourke F, Shen Q, Mak JC and Hung WT: Meta-analysis of the cardiovascular benefits of intensive lipid lowering with statins. Acta Neurol Scand 124: 188-195, 2011. 